\title{
Effectiveness of Distraction Techniques in The Management of Anxious Children in the Dental Operatory
}

\author{
Dr. Sindura Allani ${ }^{1}$, Dr. Jyothsna V Setty ${ }^{2}$ \\ ${ }^{I}$ (Department Of Pediatric And Preventive Dentistry, M.R. Ambedkar Dental College And Hospital, Bengaluru, \\ Karnataka, India)

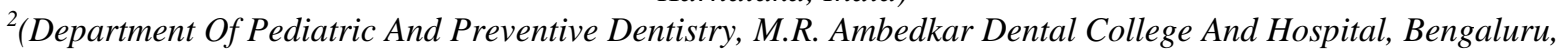 \\ Karnataka, India)
}

\begin{abstract}
Aims and objectives: To investigate the effect of distraction with a mobile phone video game in comparison with video viewing on the behavior of children undergoing local anesthesia injection during dental extraction and the treatment satisfaction as reported by children and pediatric dentists. Materials and methods: 30 children in the age group of 4-8 years with Frankel's behavior rating score of 2 who required local anesthesia for dental extraction were selected. There were two study groups; group 1 playing video game on the mobile phone and group 2 viewing videos of patient's favorite cartoon character on mobile phone as means of distraction during the preoperative period and during the course of the dental procedure. The level of anxiety of the patient and the pediatric dentist's satisfaction with the patient's behavior during the treatment were noted. Results: Mobile phone video games were found to be more effective for distracting kids in the dental operatory than viewing videos. Preoperative anxiety was found to be highly reduced with this method of distraction. Conclusion: A cartoon video or video game on a mobile phone can be offered to most children as they are easy to implement, portable, and effective method to reduce anxiety in the preoperative area and during injection of local anesthesia for dental extraction. These techniques of distraction also reduce operatory stress on the pediatric dentist.
\end{abstract}

Keywords: Cartoon videos, Dentist satisfaction, Distraction, Patient anxiety, Video games,

\section{Introduction}

Anxiety is an uneasy mental state concerning impending or anticipated illness. Dental anxiety denotes a state of apprehension in relation to dental treatment. Various methods of reducing patient anxiety have been used in dentistry. Distraction is one of them.

Distraction is the technique of diverting the patient's attention from what may be perceived as an unpleasant procedure (AAPD 2016). Mc Caul and Mallet developed the theory of distraction by placing emphasis on the fact that the capacity of humans to pay attention is limited. They pointed out that an individual should concentrate on the painful stimuli in order to perceive pain; therefore, perception of pain decreases when a person's attention is distracted away from the stimulus [1].

Distracters can be either in active or passive form. Audiovisual distraction is a mode of passively distracting two types of sensations - - hearing and seeing. Whereas, playing a game is an active technique which distracts an extra source of sensation - kinesthetic sensation. Watching videos and playing video games on mobile phones are widely popular among children. These can be used by the dentists as modes of distraction for pediatric patients. Studies on the effect of cognitive distraction in the dental operatory are limited.

Therefore, the aim of this study was to investigate the effect of distraction with a mobile phone video game in comparison with video viewing on the anxiety of children undergoing local anesthesia injection during extraction and the operator satisfaction with patients' behavior during the treatment as reported by children and pediatric dentists respectively.

\section{Materials And Methods}

This was an interventional study conducted in the department of Pediatric and Preventive Dentistry, M. R. Ambedkar Dental College and Hospital, Bangalore by a single operator. Before beginning with the study, the study design had been approved by the ethical committee of M. R. Ambedkar Dental College and Hospital, Bengaluru, Karnataka, India and a written consent was obtained from patients' parents along with brief dental and medical history of patients. As children in the age group of 4-8 year show most disruptive or negative behavior and are difficult to manage, therefore they were selected in this study. ${ }^{2}$ A convenience sample of 60 children with Frankel's behavior rating score of 2 who require local anesthesia for dental extraction were selected based on the following criteria. Inclusion criteria: Patients who require dental extraction under local anesthesia, patients with Frankel's score 2; patients who are familiar with mobile phone games; patients in the age group of 4 - 8 years who were well oriented to time and place. Exclusion criteria: Patients with medically or 
developmentally compromising conditions; patients with mental / cognitive problems; patients with heartbeat disorders; patients with photosensitive epilepsy.

Patients were randomly divided into 2 study groups with 30 in each group. Group 1 patients were given to play video game of their interest on the mobile phone and group 2 patients were given video viewing of their favorite cartoon character on mobile phone as means of distraction. The mobile phone was connected to ear phones for better audio distraction. The level of dental anxiety among the patients was recorded at four intervals of the procedure, which are:

- Before the treatment (on entering the clinic / hospital)

- After using the distraction technique pre - operatively

- During the treatment (while injecting local anaesthesia)

- After the treatment (after injecting local anaesthesia) continuing with the distraction technique.

Level of anxiety of each patient was assessed using Facial image scale through a questionnaire (Table 1). The patient was asked to select the image he can closely associate with at that moment. The ease of handling the patient (pre - operatively and during the procedure) and the ease of carrying out the procedure by the paediatric dentist after using these distraction techniques were assessed using a questionnaire on a five point Likert scale (Table 2). The results were analyzed using the following statistical techniques: a two - way repeated measure ANOVA test was used to compare the level of dental anxiety among the two study groups at four intervals. Wilcoxon Signed rank test was used to assess the ease of handling patients by the clinician at two intervals of the procedure. Mann Whitney U test was used to assess the ease of carrying out the procedure by the clinician.

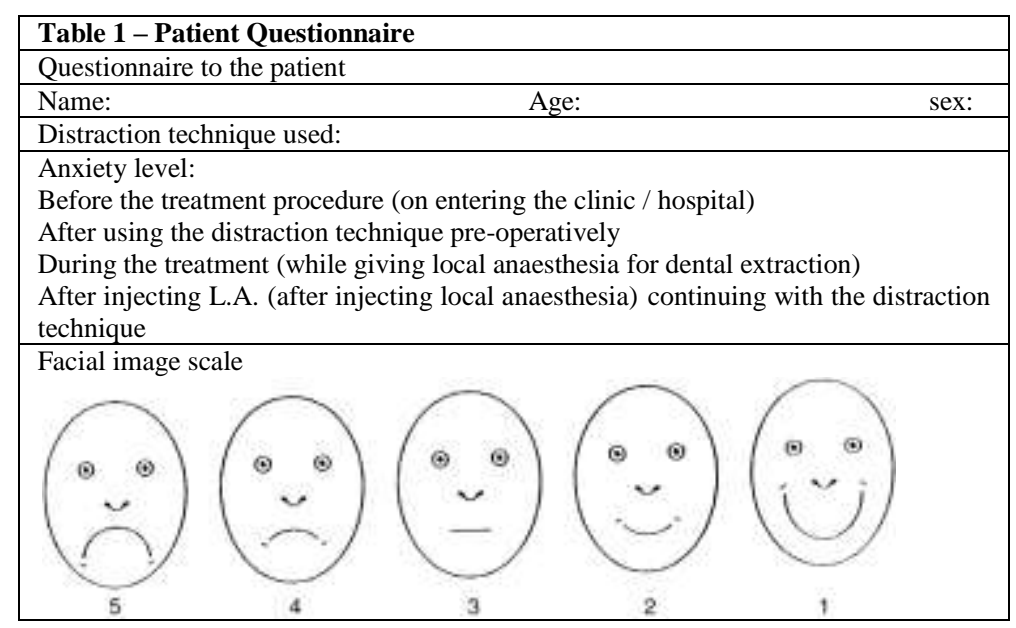

\begin{tabular}{|l|}
\hline Table 2 - Pediatric Dentist Questionnaire \\
\hline Questionnaire to the dentist \\
\hline Behavior rating of the patient before the procedure (Frankel's score): \\
\hline Distraction technique used: \\
\hline Ease of handling patients: \\
Pre-operatively \\
During the procedure \\
\hline Ease of carrying out the procedure with this distraction technique: \\
\hline Scoring: \\
Very good $=1$ \\
Good $=2$ \\
Average $=3$ \\
Not bad $=2$ \\
Bad $=1$ \\
\hline
\end{tabular}

\section{Results}

A total of 60 children (30 in each group) in the age group of 4-8 years participated in the study. The mean values of dental anxiety levels among the participants of the two groups are summarized in Table 3 and Fig. 1.

\begin{tabular}{|l|l|l|}
\hline \multicolumn{3}{|l|}{ Table 3 - Mean anxiety levels of patients in group 1 and 2 } \\
\hline Time interval & Group 1 (mean \pm SD) & Group 2 (Mean \pm SD) \\
\hline Before the treatment & $3.6 \pm 0.55$ & $3.6 \pm 0.5$ \\
\hline After using distraction technique pre-operatively & $1.9 \pm 1.2$ & $2.3 \pm 1.2$ \\
\hline During the treatment & $3.2 \pm 1.1$ & $3.4 \pm 0.7$ \\
\hline After the treatment & $2.3 \pm 1.2$ & $3.1 \pm 0.9$ \\
\hline
\end{tabular}




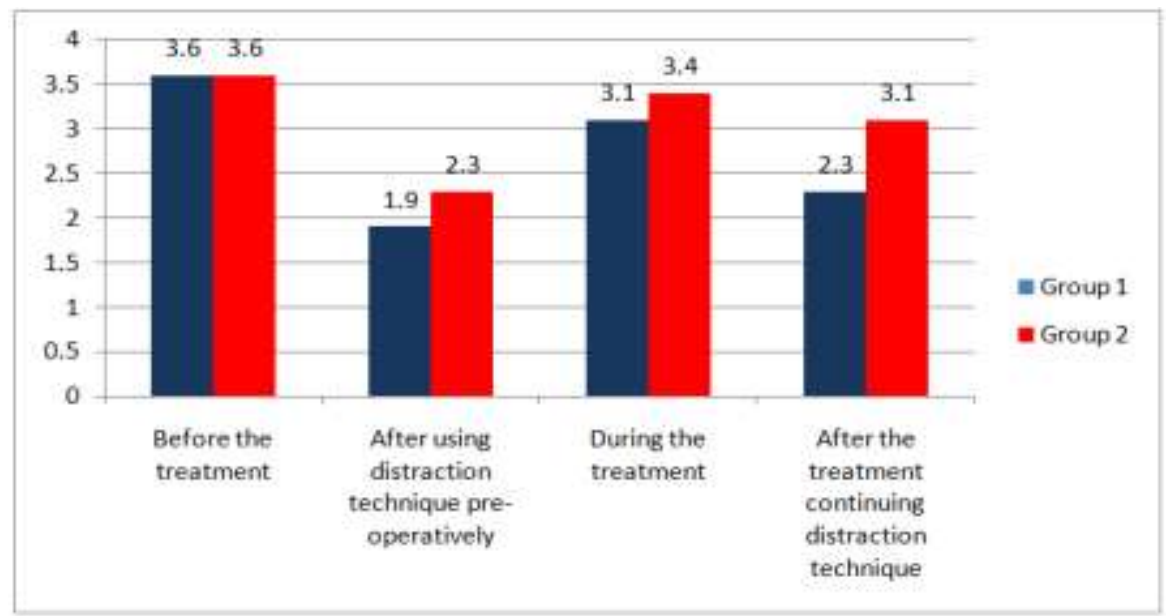

Fig. 1 - mean anxiety levels of patients in group 1 and 2

The levels of dental anxiety among the two groups were compared at four intervals of the procedure using Two way Repeated measures ANOVA (Table 4). It was seen that the difference between the interventions i.e. the two different distraction techniques was not significant. Statistical significant difference was obtained with regard to the stages 2 and 4 as compared to stage 1 of the dental procedure in both the groups.

\begin{tabular}{|l|l|}
\hline \multicolumn{2}{|l|}{ Table 4 - effect of the two interventions used } \\
\hline Source & $\mathrm{p}$ - value \\
\hline Different Interventions & 0.06 \\
\hline Different stages of procedure & $0.00 *$ \\
\hline$* \mathrm{p}<0.05$ = statistically significant. \\
\hline
\end{tabular}

The ease of handling the patient preoperatively and during the procedure among both the groups was analyzed using Wilcoxon Signed rank test (Table 5 and Fig. 2). It showed that both the distraction techniques had a statistical significant difference in relation to the ease of handling patients pre-operatively and during the procedure ( $\mathrm{p}=0.01$ for group $1, \mathrm{p}=0.04$ for group 2$)$.

\begin{tabular}{|l|l|l|l|}
\hline \multicolumn{4}{|c|}{ Table 5 - Ease of handling patients in group 1 and 2 } \\
\hline & Pre-operatively & During the procedure & p-value \\
\hline Group 1 (mean \pm SD) & $3.7 \pm 0.9$ & $3.0 \pm 1.2$ & $0.01^{*}$ \\
\hline Group 2 (mean \pm SD) & $2.9 \pm 1.1$ & $2.3 \pm 1.1$ & $0.04^{*}$ \\
\hline *p $<0.05$ = statistically significant. \\
\hline
\end{tabular}

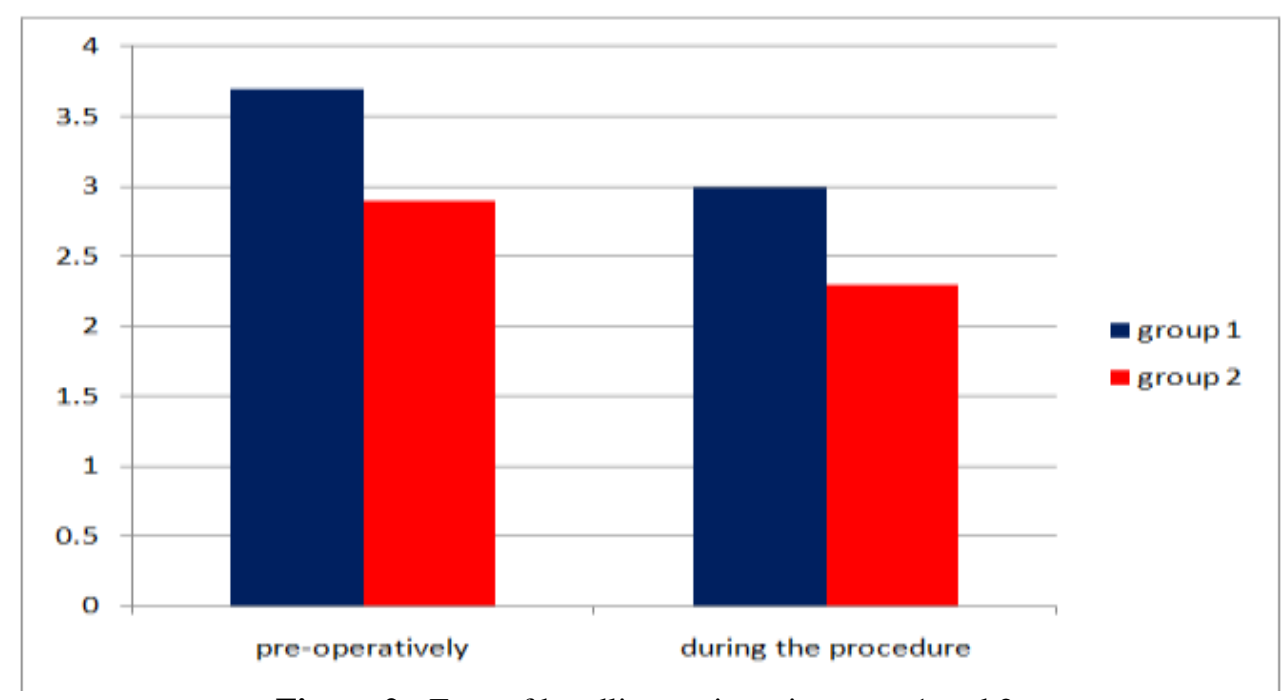

Figure 2 - Ease of handling patients in group 1 and 2 
The ease of carrying out the procedure was compared between both the groups using Mann Whitney U test (Fig. 3). It indicated that it was significantly easier to carry out the procedure on group 1 patients than on group $2(\mathrm{p}=0.045)$.

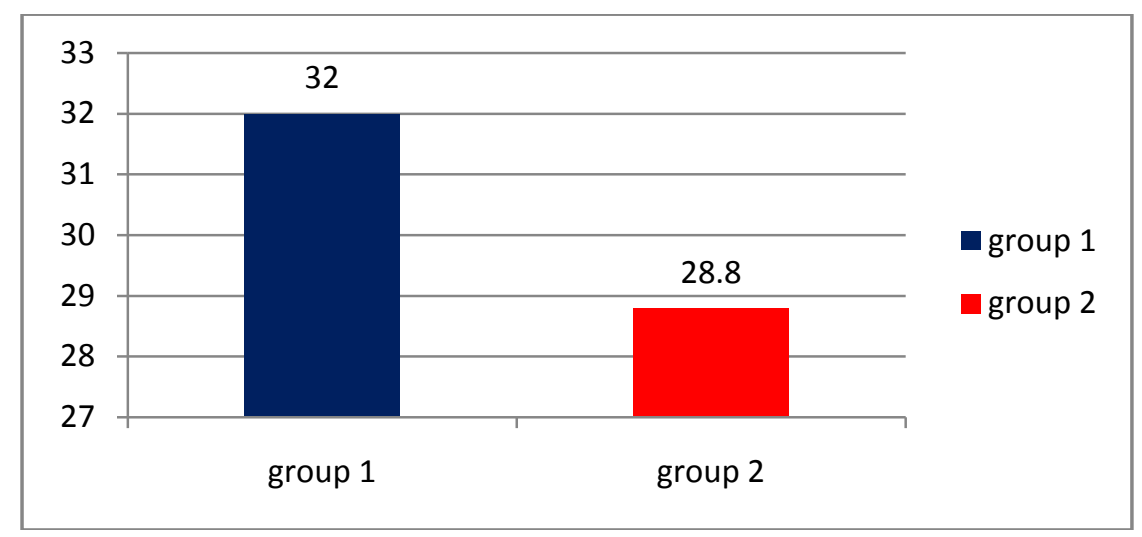

Figure 3 - ease of carrying out the procedure

\section{Discussion}

Dental anxiety is a common problem that develops mostly in childhood and adolescence [3-4]. The nature of a child's dental anxiety can vary significantly. Some children present with fears in relation to specific dental stimuli (e.g. needle or drill), other children report more generalized anxiety [5-8]. Although injecting LA is helpful for controlling pain during dental procedures, the injection itself can be painful. Needles, according to few studies are the most fearful and anxiety provoking tool in dentistry [9-11].

Distraction is a behavior management technique in which the patient is distracted away from the stimuli causing anxiety and thereby reducing it. The main objective of this technique is to relax the patient and to reduce anxiety during treatment. According to a number of studies the ideal distracter would require an optimal amount of attention involving multiple sensory modalities (visual, auditory, and kinesthetic), active emotional involvement and participation of the patient to compete with the signals from the noxious stimuli [1213].

Active forms of distraction promote a child's participation involving several sensory components such as interactive toys, virtual reality, controlled breathing, guided imagery and relaxation [14-17]; conversely, passive forms achieve distraction through a child's observation of an activity or stimulus rather than their explicit partaking for example listening to music, watching television (TV) [18-20]. Passive distraction technique used in this study was watching of cartoon shows and the active technique used was playing of video games on mobile phone.

A study conducted by Attar et al. suggested that active distraction that enhances visual, mental, and motor participation of the child patient would provide anxiolysis and analgesia that surpasses the effect of passive distraction [21].

There has been evidence from medicine that passive distraction, such as watching a film, is not as effective as active distraction (e.g. playing a video game) in reducing patient anxiety as proven by the results of this study [22-23]. Previously several paediatric hospitals have tried to utilize the iPad technology and MP3 players with soft padded headphones to support a child through painful medical procedures. They have indicated that there will be further opportunities to use tablet computers as distraction tools when caring for children [23].

Prabhakar et al. (2007) assessed child's anxiety in four dental visits - screening visit, prophylaxis visit, cavity preparation and restoration visit, and extraction visit. They found AV eyeglasses to be more effective than audio distraction [20]. Comparing three distraction techniques for reducing stress in patients (an audiocomedy program, a video-comedy program, and a video game), Seyrek et al. found that video program and video games were more effective than the audio program. Results further suggested that successful distraction was accompanied by an increase in physiological arousal, possibly indicating the degree of psychological absorption or engagement in the video [24].

The results of this study showed that patient anxiety after using both the techniques while delivering local anesthesia during dental extraction and continuing the distraction techniques after completion of the dental procedure was significantly lower than the pre-operative anxiety. As per this study playing a video game, which acts as an active distraction technique, reduces patient anxiety better than passively watching cartoon shows although the results were not statistically significant.

Virtual reality immersion has been shown to be somewhat more effective than audio visual distraction because it augments detachment from viewing and hearing what is happening in the environment [25]. This

DOI: 10.9790/0853-1510026973 $\quad$ www.iosrjournals.org $\quad 72 \mid$ Page


study has used mobile phone video games instead of virtual reality eye wear as they are easily available, cost effective, portable, popular and well known among kids of all age ranges and socio economic groups.

Although it has been hypothesized that active strategies are more effective than the passive ones, studies conducted by Peretz B et al., Mason S et al and Dahlquist LM et al suggested that passive distraction may be as effective or even better, since, the active forms are too demanding for children [15, 26-27].

In this study it was found that it was significantly easier to carry out the procedure using active video game distraction than passive video viewing of cartoons. Both the distraction techniques were found to be very effective in relation to handling patients pre-operatively and during the procedure. The above said two parameters (ease of carrying out the procedure and ease of handling patients) were hitherto not found to be noted in literature in any studies, therefore, were not comparable.

\section{Conclusion}

A cartoon video or video game on a mobile phone can be offered to most children as they are easy to implement, portable, and effective method to reduce anxiety in the preoperative area and during induction of local anesthesia for dental extraction.

\section{References}

[1]. McCaul KD, Malott JM, Distraction and coping with pain, Psychological bulletin., 95 (3), 1984, 516-533.

[2]. Ram D, Shapira J, Holan G, Magora F, Cohen S, Davidovich E, Audiovisual video eyeglass distraction during dental treatment in children, Quintessence international, 41 (8), 2010, 671:673.

[3]. Wismeijer AA, Vingerhoets AJ, The use of virtual reality and audiovisual eyeglass systems as adjunct analgesic techniques: a review of the literature. Annals of Behavioral Medicine, 30 (3), 2005, 268-78.

[4]. Slifer KJ, Tucker CL, Dahlquist LM, Helping children and caregivers cope with repeated invasive procedures: How are we doing?, Journal of Clinical Psychology in Medical Settings, 9 (2), 2002, 131-52.

[5]. van Wijk AJ, Hoogstraten J, Anxiety and pain during dental injections, Journal of dentistry, 37 (9), 2009, $700-4$.

[6]. Hembrecht EJ, Nieuwenhuizen J, Aartman IH, Krikken J, Veerkamp JS, Pain-related behaviour in children: a randomised study during two sequential dental visits, European Archives of Paediatric Dentistry, 14 (1), 2013, 3-8.

[7]. El-Sharkawi HF, El-Housseiny AA, Aly AM, Effectiveness of new distraction technique on pain associated with injection of local anesthesia for children, Pediatric dentistry, 34 (2), 2012, 35E-8E.

[8]. Locker D, Liddell A, Dempster L, Shapiro D, Age of onset of dental anxiety, Journal of dental research, 78 (3), 1999, 790-6.

[9]. Locker D, Thomson WM, Poulton R, Onset of and patterns of change in dental anxiety in adolescence and early adulthood: a birth cohort study, Community dental health, 18 (2), 2001, 99-104.

[10]. Taani DQ, El-Qaderi SS, Abu Alhaija ES, Dental anxiety in children and its relationship to dental caries and gingival condition. International journal of dental hygiene, 3 (2), 2005, 83-7.

[11]. Rantavuori K, Lahti S, Hausen H, Seppä L, Kärkkäinen S, Dental fear and oral health and family characteristics of Finnish children, Acta Odontologica Scandinavica, 62 (4), 2004, 207-13

[12]. Peretz B, Efrat J, Dental anxiety among young adolescent patients in Israel. International Journal of Paediatric Dentistry, 10 (2), 2000, 126-32.

[13]. Rantavuori K, Lahti S, Seppä L, Hausen H, Dental fear of Finnish children in the light of different measures of dental fear, Acta odontologica Scandinavica, 63 (4), 2005, 239-44.

[14]. Patel A, Schieble T, Davidson M, Tran MC, Schoenberg C, Delphin E, Bennett H, Distraction with a hand-held video game reduces pediatric preoperative anxiety, Pediatric Anesthesia, 16 (10), 2006, 1019-27.

[15]. Peretz B, Gluck GM, Assessing an active distracting technique for local anesthetic injection in pediatric dental patients: repeated deep breathing and blowing out air, The Journal of clinical pediatric dentistry, 24 (1), 1998, 5-8.

[16]. Weydert JA, Shapiro DE, Acra SA, Monheim CJ, Chambers AS, Ball TM, Evaluation of guided imagery as treatment for recurrent abdominal pain in children: a randomized controlled trial, BMC paediatrics, 6 (1), 2006, 1.

[17]. Nilsson S, Finnström B, Kokinsky E, Enskär K, The use of Virtual Reality for needle-related procedural pain and distress in children and adolescents in a paediatric oncology unit, European Journal of Oncology Nursing, 13 (2), 2009, 102-9.

[18]. Aitken JC, Wilson S, Coury D, Moursi AM, The effect of music distraction on pain, anxiety and behavior in pediatric dental patients, Pediatric dentistry, 24 (2), 2002, 114-8.

[19]. Marwah N, Prabhakar AR, Raju OS, Music distraction-Its efficacy in management of anxious pediatric dental patients, Journal of Indian Society of Pedodontics and Preventive Dentistry, 23 (4), 2005, 168

[20]. Prabhakar AR, Marwah N, Raju OS, A comparison between audio and audiovisual distraction techniques in managing anxious pediatric dental patients, Journal of Indian Society of Pedodontics and Preventive Dentistry, 25 (4), 2007, 177.

[21]. Lacquiere DA, Courtman, Use of the iPad in paediatric anaesthesia, Anaesthesia, 66 (7), 2011, 629-30.

[22]. McQueen A, Cress C, Tothy A, Using a tablet computer during pediatric procedures: a case series and review of the "apps", Pediatric emergency care, 28 (7), 2012, 712-4.

[23]. Attar RH, Baghdadi ZD, Comparative efficacy of active and passive distraction during restorative treatment in children using an iPad versus audiovisual eyeglasses: a randomised controlled trial, European Archives of Paediatric Dentistry, 16 (1), 2015, 1-8.

[24]. Seyrek SK, Corah NL, Pace LF, Comparison of three distraction techniques in reducing stress in dental patients, The Journal of the American Dental Association, 108 (3), 1984, 327-9.

[25]. Leibovici V, Magora F, Cohen S, Ingber A, Effects of virtual reality immersion and audiovisual distraction techniques for patients with pruritus. Pain Research and Management, 14 (4), 2009, 283-6.

[26]. Mason S, Johnson MH, Woolley C, A comparison of distractors for controlling distress in young children during medical procedures. Journal of Clinical Psychology in Medical Settings, 6 (3), 1999, 239-48.

[27]. Dahlquist LM, McKenna KD, Jones KK, Dillinger L, Weiss KE, Ackerman CS, Active and passive distraction using a headmounted display helmet: effects on cold pressor pain in children, Health Psychology, 26 (6), 2007, 794. 